\title{
Light-dependent microbial metabolisms drive carbon fluxes on glacier surfaces
}

\author{
Andrea Franzetti ${ }^{1}$, Ilario Tagliaferri ${ }^{1}$, Isabella Gandolfi ${ }^{1}$, Giuseppina Bestetti ${ }^{1}$, \\ Umberto Minora ${ }^{2,4}$, Christoph Mayer ${ }^{3}$, Roberto S Azzoni ${ }^{2}$, Guglielmina Diolaiuti², \\ Claudio Smiraglia ${ }^{2}$ and Roberto Ambrosini ${ }^{1}$ \\ ${ }^{1}$ Department of Earth and Environmental Sciences (DISAT), University of Milano-Bicocca, Milano, Italy; \\ 2 “A. Desio” Department of Earth Sciences, Università degli Studi di Milano, Milano, Italy and ${ }^{3}$ Bavarian \\ Academy of Sciences and Humanities, Munich, Germany
}

\begin{abstract}
Biological processes on glacier surfaces affect glacier reflectance, influence surface energy budget and glacier response to climate warming, and determine glacier carbon exchange with the atmosphere. Currently, carbon balance of supraglacial environment is assessed as the balance between the activity of oxygenic phototrophs and the respiration rate of heterotrophic organisms. Here we present a metagenomic analysis of tiny wind-blown supraglacial sediment (cryoconite) from Baltoro (Pakistani Karakoram) and Forni (Italian Alps) glaciers, providing evidence for the occurrence in these environments of different and previously neglected metabolic pathways. Indeed, we observed high abundance of heterotrophic anoxygenic phototrophs, suggesting that light might directly supplement the energy demand of some bacterial strains allowing them to use as carbon source organic molecules, which otherwise would be respired. Furthermore, data suggest that $\mathrm{CO}_{2}$ could be produced also by microbiologically mediated oxidation of $\mathrm{CO}$, which may be produced by photodegradation of organic matter.
\end{abstract}

The ISME Journal (2016) 10, 2984-2988; doi:10.1038/ismej.2016.72; published online 29 April 2016

Climate change is determining a global cryosphere shrinkage and mountain glacier environments are declining (IPPC, 2014). The consequent loss of biodiversity is yet to be fully assessed, particularly the loss of functional biodiversity in extreme environments (Stibal et al., 2012; Boetius et al., 2015). Cryoconite holes, that is, small depressions on glacier surfaces whose formation is because of windborne debris (cryoconite), are the most biologically active environments on glaciers (Boetius et al., 2015).

We used whole-metagenomic sequencing to investigate the main functions of six cryoconite holes from Forni (Italian Alps) and six from Baltoro (Pakistani Karakoram) glaciers. We focused on carbon and energy metabolisms by comparing the total coverage of marker genes for photosynthesis, use of inorganic and organic compounds as energy source and autotrophy/heterotrophy. We also used metagenomic sequences for the taxonomic attribution of microorganisms carrying specific metabolic genes

Correspondence: A Franzetti, Department of Earth and Environmental Sciences (DISAT), University of Milano-Bicocca, Piazza della Scienza 1, Milano 20126, Italy.

E-mail: andrea.franzetti@unimib.it

${ }^{4}$ Present address: Dipartimento di Ingegneria Civile e Ambientale, Politecnico di Milano, Milano, Italy.

Received 2 November 2015; revised 17 March 2016; accepted 29 March 2016; published online 29 April 2016
(Supplementary Figures S3 and Supplementary data set 1). Supplementary Table S4 reports the marker genes whose coverage (mean number per base of reads mapping the genes) was used to infer the abundance of each metabolism. Supplementary Table S5 and Figure 1 report their normalized coverages. Finally, we measured chemical/physical parameters of cryoconite holes and oxygen consumption rates on the days of sampling, both under light and dark conditions (Supplementary Table S3 and Supplementary Figure S2). The main hypothesis tested was whether oxygenic phototrophy and organotrophic respiration represent the only significant metabolisms affecting carbon balance on glacier surface, as currently conceived, or other microbial processes could contribute to it.

On the basis of $16 \mathrm{~S}$ rRNA gene sequencing, Cyanobacteria represented 22 and $3 \%$ of the microbial community on Forni and Baltoro, respectively (Supplementary Figure S3). High abundance of cyanobacteria has been already observed in polar and alpine cryoconite (Segawa et al., 2014; Stibal et al., 2014), whereas low abundance was reported on Rotmoosferner Glacier (Tirol, Austria; Edwards et al., 2013). Consistently, coverage of psbD (photosystem II P680 reaction center D2 protein gene) was (mean \pm s.e.) $128.0 \pm 9.5$ on Forni and $74.5 \pm 12.5$ on Baltoro, similar to that reported for Arctic and Antarctic supraglacial microbial mats (Varin et al., 2013). 
Phototrophy

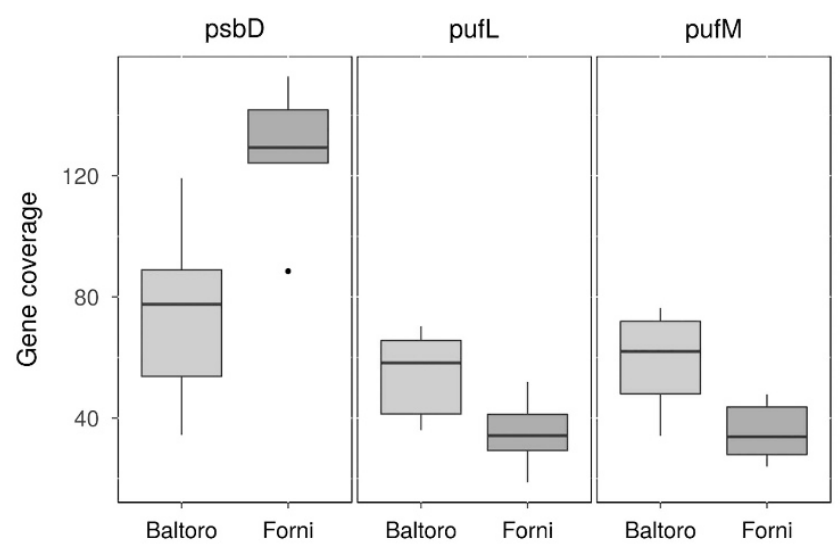

Autotrophy

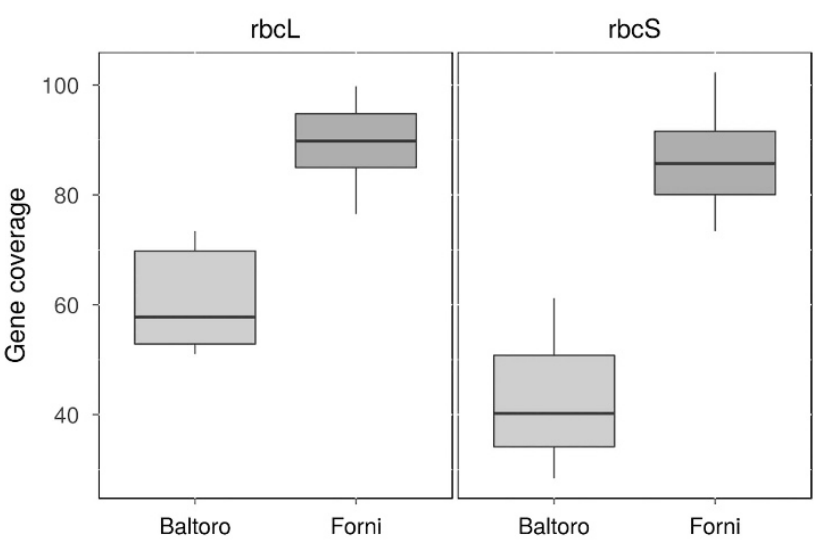

Chemolithotrophy
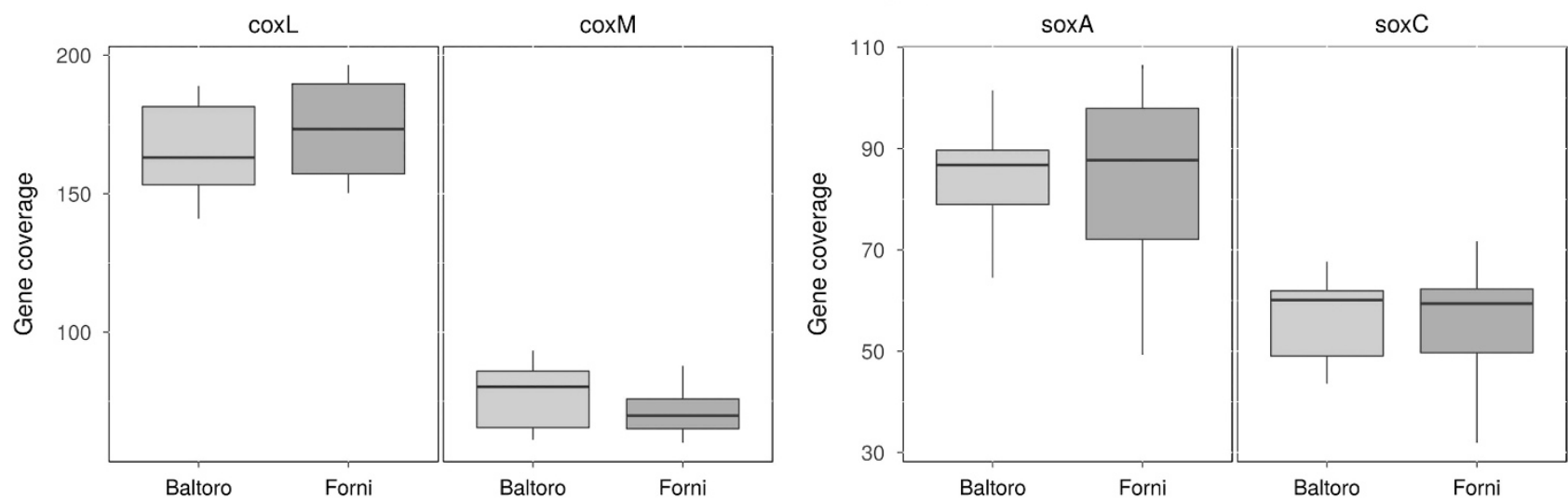

Biodegradation of natural polymers
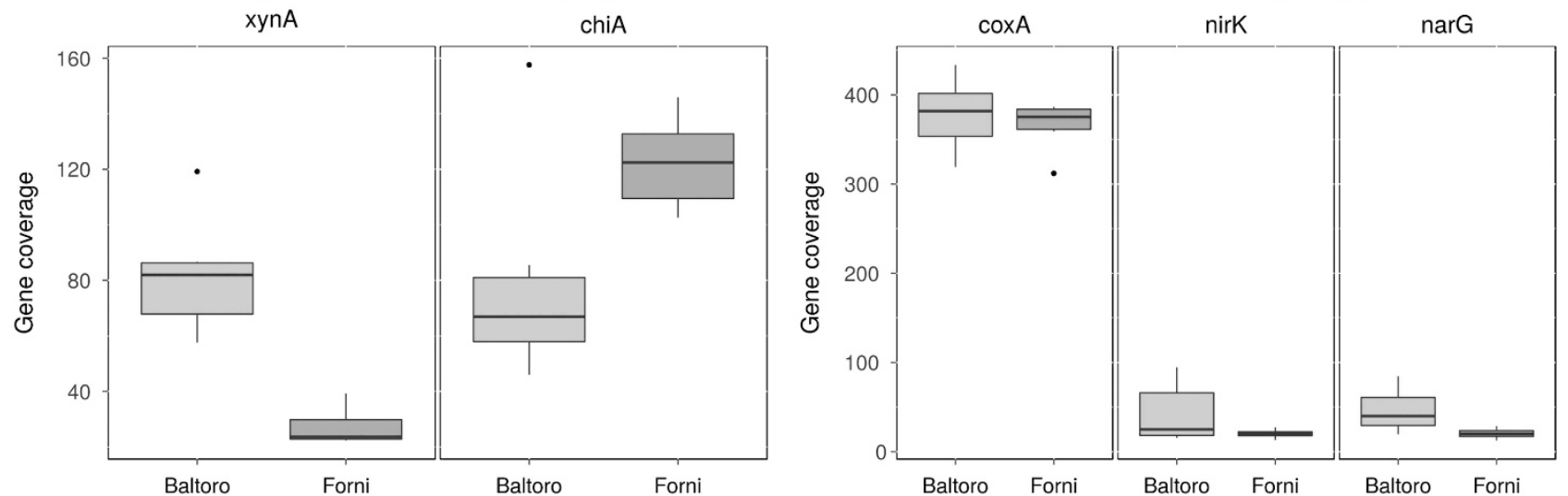

Figure 1 Box plots of marker gene coverages in Forni and Baltoro cryoconite metagenomes. chiA, chitinase; coxA, cytochrome $c$ oxidase subunit I; coxML, carbon-monoxide dehydrogenase medium and large subunits; narG, nitrate reductase alpha subunit; nirK, nitrite reductase; $p s b \mathrm{D}$, photosystem II P680 reaction center D2 protein; pufLM, photosynthetic reaction center L and M subunits; rbcLS, ribulose bisphosphate carboxylase (RubisCO); soxAC, sulfur-oxidizing proteins SoxAC; xynA, endo-1,4-beta-xylanase.

This suggests that oxygenic photosynthesis is among the dominant metabolisms in cryoconite holes. The significantly higher coverage of the $p s b \mathrm{D}$ gene on Forni than on Baltoro (Mann-Whitney $U$-test: $U=34$, $P=0.009)$ is consistent with the higher oxygen concentrations in cryoconite hole water observed on this glacier $(U=36, P=0.005)$. However, on the days of sampling, we observed strong oxygenic phototrophic activities in only two out of six holes on Forni (Supplementary Table S3). The high pufLM (photosynthetic reaction center $\mathrm{L}$ and $\mathrm{M}$ subunits) gene coverage, mostly affiliated to Proteobacteria (Supplementary Figures S3), suggests that aerobic anoxygenic phototrophs (AAPs) may contribute to energy input of the ecosystem (Yurkov and Hughes, 2013). AAPs are obligate heterotrophic phototrophs 
whose presence has been recently documented in cold environments. AAPs use light to supplement their metabolic demands and organic molecules as carbon source: under light conditions, they replace oxidative respiration with photophosphorylation, thus saving carbon, which is used in anabolic reactions for building cell biomass (Čuperová et al., 2013; Caliz and Casamayor, 2014). Interestingly, puf gene coverages were significantly higher on Baltoro than on Forni $(U \geqslant 31, P \leqslant 0.041)$, where oxygen consumption rates were also higher in dark conditions ( $U=21, P=0.041)$, when AAPs switch to a more respiratory metabolism. In contrast, oxygen consumption rates in light conditions were similar on the two glaciers $(U=23, P=0.485)$.

$\mathrm{CO}_{2}$ fixation was also widespread and almost completely achieved through the Calvin-Benson cycle, as revealed by the high coverages of rbcLS genes (ribulose bisphosphate carboxylase (RubisCO)), mostly affiliated to Proteobacteria (Supplementary Figures S3), and by the negligible presence of reductive acetyl-CoA pathway and reductive citric acid cycle (details not shown). Although the taxonomic attribution of $r b c L S$ genes showed that autotrophs mainly belonged to Cyanobacteria, it also revealed that Proteobacteria substantially contribute to $\mathrm{CO}_{2}$ fixation. Indeed, Proteobacteria represented $16-22 \%$ of bacteria harboring $r b c \mathrm{~L}$ genes, respectively, on Forni and Baltoro (Supplementary Figures S3). This suggests that autotrophic chemolithotrophs might also occur in cryoconite. Indeed, high coverages of sulfur oxidation genes (soxAC) and carbon-monoxide (CO) oxidation genes (coxLM) were detected on both glaciers. Conversely, no presence of amoAB was detected, suggesting the low relevance of ammonia oxidation and nitrification processes. sox gene clusters have been described in both anoxygenic sulfur-oxidizing phototrophs and chemolitotrophs (Friedrich et al., 2005). CO oxidizers are a phylogenetically diverse group of bacteria inhabiting different environments (King and Weber, 2007). Interestingly, CO can form rapidly from organic carbon (OC) in melting snow exposed to light (Haan et al., 2001; Xie and Zafiriou, 2009). We speculate that CO oxidizers occur in the melting snow cover of glaciers, and then persist on glacier surfaces, where photochemical CO production may occur, owing to high light intensity and abundant organic matter (OM) in cryoconite (Supplementary Table S3 and Supplementary Figure S1). Direct measurements of CO in the holes are not available; however, CO photochemical formation rates were found to be correlated with the concentrations of dissolved OC (DOC) in the snow (Haan et al., 2001). DOC, in turn, seems more abundant in mountain glacier cryoconite (0.71 $\mathrm{mg} \mathrm{l}^{-1}$; Hood et al., 2015) than in the snow (0.07-0.30 $\mathrm{mg} \mathrm{l}^{-1}$; Legrand et al., 2013). Therefore, despite we have no direct evidence that CO actually forms in cryoconite holes and to which amount, it might represent a bioavailable substrate on glacier surface, which supplements the energy demand of microbial populations through its oxidation to $\mathrm{CO}_{2}$ (King and Weber, 2007). Importantly, cyanobacteria produce extracellular polymeric substances (EPSs) that represent an important DOC component (Bhatia et al., 2010). Hence, oxygenic phototrophs may contribute to the amount of DOC in the cryoconite, which in turn might be photodegraded to $\mathrm{CO}$ and sustain CO oxidizers. Surprisingly, CO oxidizers have not been reported in glacier environments previously, probably because of the lack of functional studies on these environments. However, phylogenetic assignment of the coxM gene revealed that CO oxidizers mostly belonged to Actinobacteria (up to $26 \%$ ), $\alpha$ - (up to $25 \%$ ) and $\beta$-Proteobacteria (up to $69 \%$ ), particularly Comamonadaceae (34\% on Baltoro; Supplementary Figures S3), which are known to occur on glacier surfaces (Edwards et al., 2014; Boetius et al., 2015). To gain more insight into the role of Comamonadaceae, we reconstructed from metagenomic data 10 partial genomes of Polaromonas (Supplementary Figure S4), a genus of Comamonadaceae, which is ubiquitous in glacial environments (Darcy et al., 2011; Michaud et al., 2012; Franzetti et al., 2013). Genome annotation revealed widespread presence of CO dehydrogenase and absence of a complete $\mathrm{CO}_{2}$ fixation pathway (Supplementary Table S6), consistently with the complete genome of Polaromonas JS666. This suggests that Polaromonas in cryoconite might use $\mathrm{CO}$ as energy source in presence of OC (mixotrophy) (Mattes et al., 2008).

We observed high coverages of genes coding for enzymes involved in the use of several OC sources,

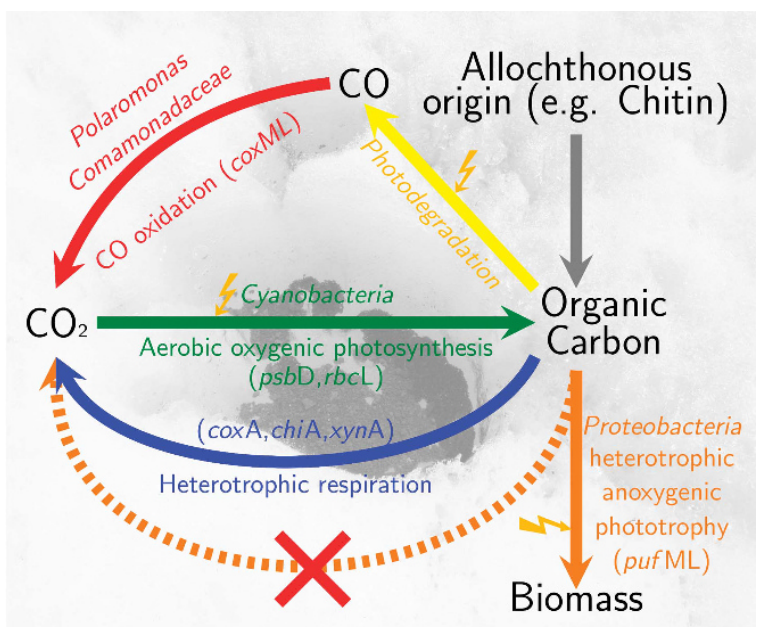

Figure 2 Proposed cryoconite carbon interactome. The main inferred carbon metabolisms and reactions are reported with the taxonomic affiliation of the microorganisms carrying out these metabolisms. Microorganisms involved in heterotrophic respiration are not reported because they belong to many different taxa. Lightning symbols represent light energy involvement into the reaction. Heterotrophic anoxygenic phototrophs use light as energy source in anabolic reactions (orange arrow), thus producing biomass from organic carbon, which otherwise would be respired to $\mathrm{CO}_{2}$ (dashed orange arrow with a red cross). 
such as cellulose, EPSs produced by cyanobacteria (xylA) and chitin (chiA). Furthermore, measures revealed that cryoconite holes were fully oxygenated environments. This condition explains the very high coverages of cytochrome $C$ oxidase subunit I gene ( $\operatorname{coxA})$. However, we observed also the presence of nirK/narG genes, which suggest the occurrence of anaerobic conditions. Conversely, the abundance of marker genes for dissimilatory sulfate reduction (dsrAB) was negligible.

In summary, supraglacial bacterial communities exhibit a high functional biodiversity as they can exploit OC both as energy and carbon source. The high solar radiation at glacier surface may favor both oxygenic and anoxygenic photosynthesis, likely by organisms with both pure autotrophic and mixotrophic lifestyles. Light might also support photochemical CO production and its microbiologically mediated consumption (Figure 2). Despite the presence of the genetic potential for the abovedescribed metabolisms does not necessarily imply that they are actually active, we propose that models of carbon fluxes on glacier surfaces should integrate also alternative metabolisms that has been overlooked so far, such as anoxygenic photosynthesis and CO oxidation.

\section{Conflict of Interest}

The authors declare no conflict of interest.

\section{Acknowledgements}

We thank Parco Tecnologico Padano (Lodi, Italy) for technical assistance and sequencing. We also thank EvK2-CNR association for support and logistics during expedition on Baltoro Glacier. This work was partially funded by the Italian Ministry of Research (PRIN grant 2010AYKTAB to CS) and by University of Milano-Bicocca (grant 7-19-2001100-2 to RA). Bioinformatics analyses have been run on PICO server (CINECA, Bologna, Italy; project MEGABIT—grant ID: HP10CLG7F to AF).

\section{Data Accessibility}

Sequence data of metagenomes were submitted to European Nucleotide Archive (ENA), study accession number PRJEB12327 (http://www.ebi.ac.uk/ ena/data/view/PRJEB12327).

\section{References}

Bhatia MP, Das SB, Longnecker K, Charette MA, Kujawinski EB. (2010). Molecular characterization of dissolved organic matter associated with the Greenland ice sheet. Geochim Cosmochim Acta 74: 3768-3784.

Boetius A, Anesio AM, Deming JW, Mikucki JA, Rapp JZ. (2015). Microbial ecology of the cryosphere: sea ice and glacial habitats. Nat Rev Microbiol 13: 677-690.
Caliz J, Casamayor EO. (2014). Environmental controls and composition of anoxygenic photoheterotrophs in ultraoligotrophic high-altitude lakes (Central Pyrenees). Environ Microbiol Rep 6: 145-151.

Čuperová Z, Holzer E, Salka I, Sommaruga R, Koblízek M. (2013). Temporal changes and altitudinal distribution of aerobic anoxygenic phototrophs in mountain lakes. Appl Environ Microbiol 79: 6439-6446.

Darcy JL, Lynch RC, King AJ, Robeson MS, Schmidt SK. (2011). Global distribution of Polaromonas phylotypes - evidence for a highly successful dispersal capacity. PLoS One 6: e23742.

Edwards A, Mur LAJ, Girdwood SE, Anesio AM, Stibal M, Rassner SME et al. (2014). Coupled cryoconite ecosystem structure-function relationships are revealed by comparing bacterial communities in alpine and Arctic glaciers. FEMS Microbiol Ecol 89: 222-237.

Edwards A, Pachebat JA, Swain M, Hegarty M, Hodson AJ, Irvine-Fynn TDL et al. (2013). A metagenomic snapshot of taxonomic and functional diversity in an alpine glacier cryoconite ecosystem. Environ Res Lett 8: 035003.

Franzetti A, Tatangelo V, Gandolfi I, Bertolini V, Bestetti G, Diolaiuti G et al. (2013). Bacterial community structure on two alpine debris-covered glaciers and biogeography of Polaromonas phylotypes. ISME $J$ 7: 1483-1492.

Friedrich CG, Bardischewsky F, Rother D, Quentmeier A, Fischer J. (2005). Prokaryotic sulfur oxidation. Curr Opin Microbiol 8: 253-259.

Haan D, Zuo Y, Gros V, Brenninkmeijer CAM. (2001). Photochemical production of carbon monoxide in snow. J Atmos Chem 40: 217-230.

Hood E, Battin TJ, Fellman J, O’Neel S, Spencer RGM. (2015). Storage and release of organic carbon from glaciers and ice sheets. Nat Geosci 8: 91-96.

IPPC - Intergovernmental Panel on Climate Change. (2014). Climate Change 2013 - The Physical Science Basis: Working Group I Contribution to the Fifth Assessment Report of the Intergovernmental Panel on Climate Change. Cambridge University Press: Cambridge, UK.

King GM, Weber CF. (2007). Distribution, diversity and ecology of aerobic CO-oxidizing bacteria. Nat Rev Microbiol 5: 107-118.

Legrand M, Preunkert S, Jourdain B, Guilhermet J, Faïn X, Alekhina I et al. (2013). Water-soluble organic carbon in snow and ice deposited at Alpine, Greenland, and Antarctic sites: a critical review of available data and their atmospheric relevance. Clim Past 9: 2195-2211.

Mattes TE, Alexander AK, Richardson PM, Munk AC, Han CS, Stothard $\mathrm{P}$ et al. (2008). The genome of Polaromonas sp strain JS666: Insights into the evolution of a hydrocarbon- and xenobiotic-degrading bacterium, and features of relevance to biotechnology. Appl Environ Microbiol 74: 6405-6416.

Michaud L, Caruso C, Mangano S, Interdonato F, Bruni V, Lo Giudice A. (2012). Predominance of Flavobacterium, Pseudomonas, and Polaromonas within the prokaryotic community of freshwater shallow lakes in the northern Victoria Land, East Antarctica. FEMS Microbiol Ecol 82: 391-404.

Segawa T, Ishii S, Ohte N, Akiyoshi A, Yamada A, Maruyama $\mathrm{F}$ et al. (2014). The nitrogen cycle in cryoconites: naturally occurring nitrification-denitrification granules on a glacier. Environ Microbiol 16: 3250-3262. 
Stibal M, Sabacká M, Žárský J. (2012). Biological processes on glacier and ice sheet surfaces. Nat Geosci 5: 771-774.

Stibal M, Schostag M, Cameron KA, Hansen LH, Chandler DM, Wadham JL et al. (2014). Different bulk and active bacterial communities in cryoconite from the margin and interior of the Greenland ice sheet. Environ Microbiol Rep 7: 293-300.

Varin T, Lovejoy C, Jungblut AD, Vincent WF, Corbeil J, Edwards A et al. (2013). Metagenomic analysis of stress genes in microbial mat communities from Antarctica and the High Arctic. Appl Environ Microbiol 78: 035003.

Xie H, Zafiriou OC. (2009). Evidence for significant photochemical production of carbon monoxide by particles in coastal and oligotrophic marine waters. Geophys Res Lett 36: L23606.

Yurkov V, Hughes E. (2013). Genes associated with the peculiar phenotypes of the aerobic anoxygenic phototrophs. Adv Bot Res 66: 327-358.

Supplementary Information accompanies this paper on The ISME Journal website (http://www.nature.com/ismej) 